\title{
Storytelling across social divides
}

Dr Joanna Wheeler's research has been conducted through her role as a Marie Curie Research Fellow at the
Centre for Trust, Peace Centre for Trust, Peace and Social Relations at Coventry University. Her interests lie in increasing inclusion among this, she explores storytelling and other creative methods to bridge social divides. Most importantly, Dr Wheeler advocates for intersectional participatory action research This, she contends, can help to generate understanding of differences and overcome by exclusionary narratives, such by exclusionary narratives,

\section{world tend to separate those world tend to separate those
who belong from those who do not. In this sense, they are} fundamentally exclusionary. That's why Dr Joanna Wheeler of the Centre for Trust, Peace and Social Relations has focused her research on creating new divides and help to foster a sense of inclusion and belonging.

To achieve this, Dr Wheeler has spent her time working with the most marginalised communities, in many contexts. She uses creative methods and storytelling through intersection participatory action research (PAR). Her writings explain why this method overcomes the problems that researchers face in understanding complex issues. She also details case studies to reveal the practical uses of

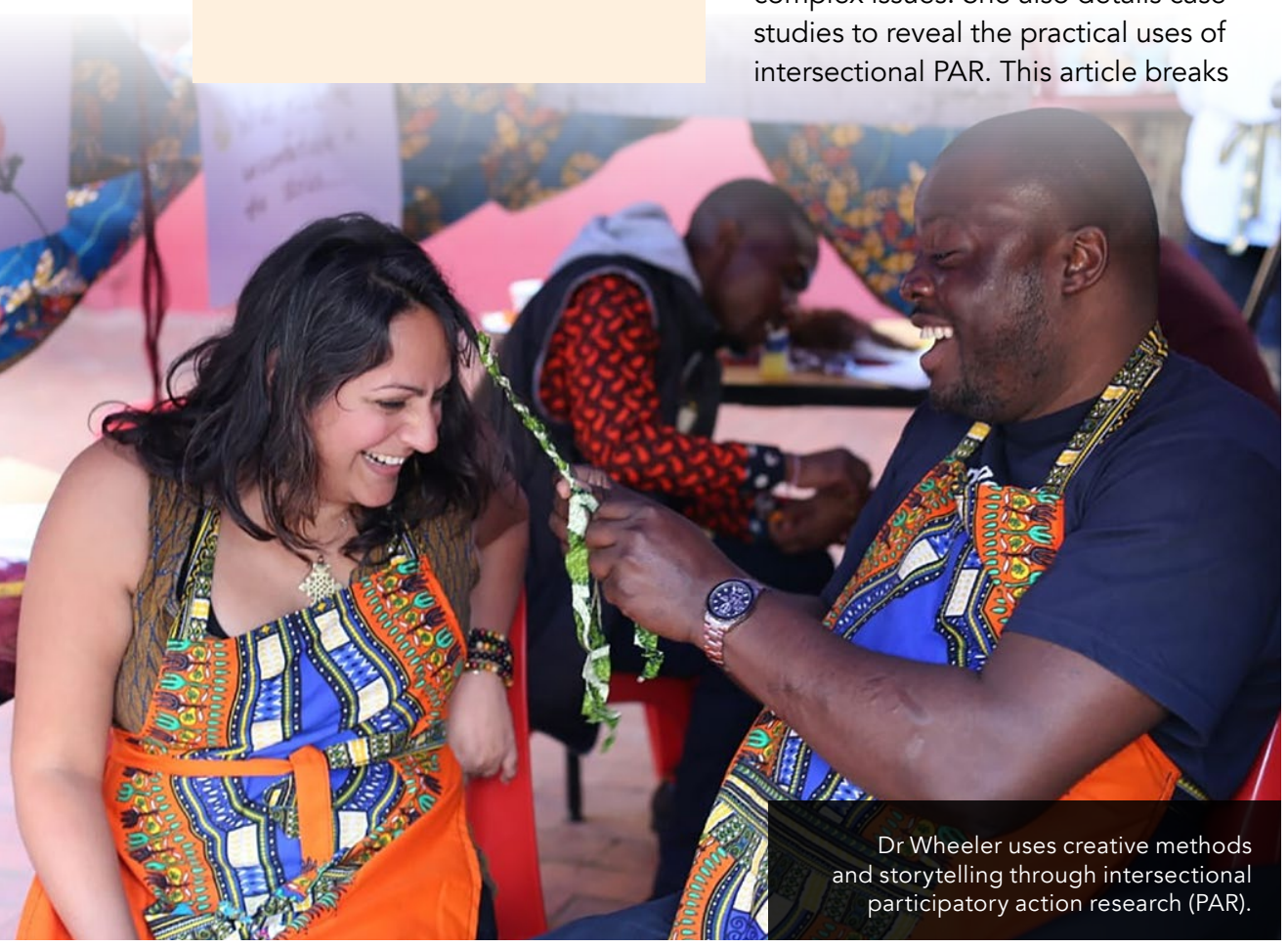

down her approach to storytelling across social divides and looks into the lessons that Dr Wheeler has learned

INTERSECTIONALITY AND PARTICIPATORY ACTION RESEARCH

DrWheeler, in putting advocating for explaining her research approach. First ty, this includes intersectionality, defined as how people experience identities such as class, race, age, gender, sexuality ability, and ethnicity, and how such a socially constructed identity constrains or opens up opportunities.

An intersectional approach is a political commitment to understanding identities and recognising how they impact on people's paths through life. In the world of narratives, this could the hero and the effect this could have the chances for women and black people to find success.

Participatory Action Research (PAR), meanwhile, is an activist's approach to academic research. This means that the research is not just an attempt to understand the world, but also to change it. Researchers are both participating in the subject in they're trying to explain - in Dr Wheeler's case, the role of storytelling on challenging inequalities - and taking action to bring about changes.

STORYTELLING: THE

INTERSECTIONAL APPROACH

If exclusionary narratives lead to

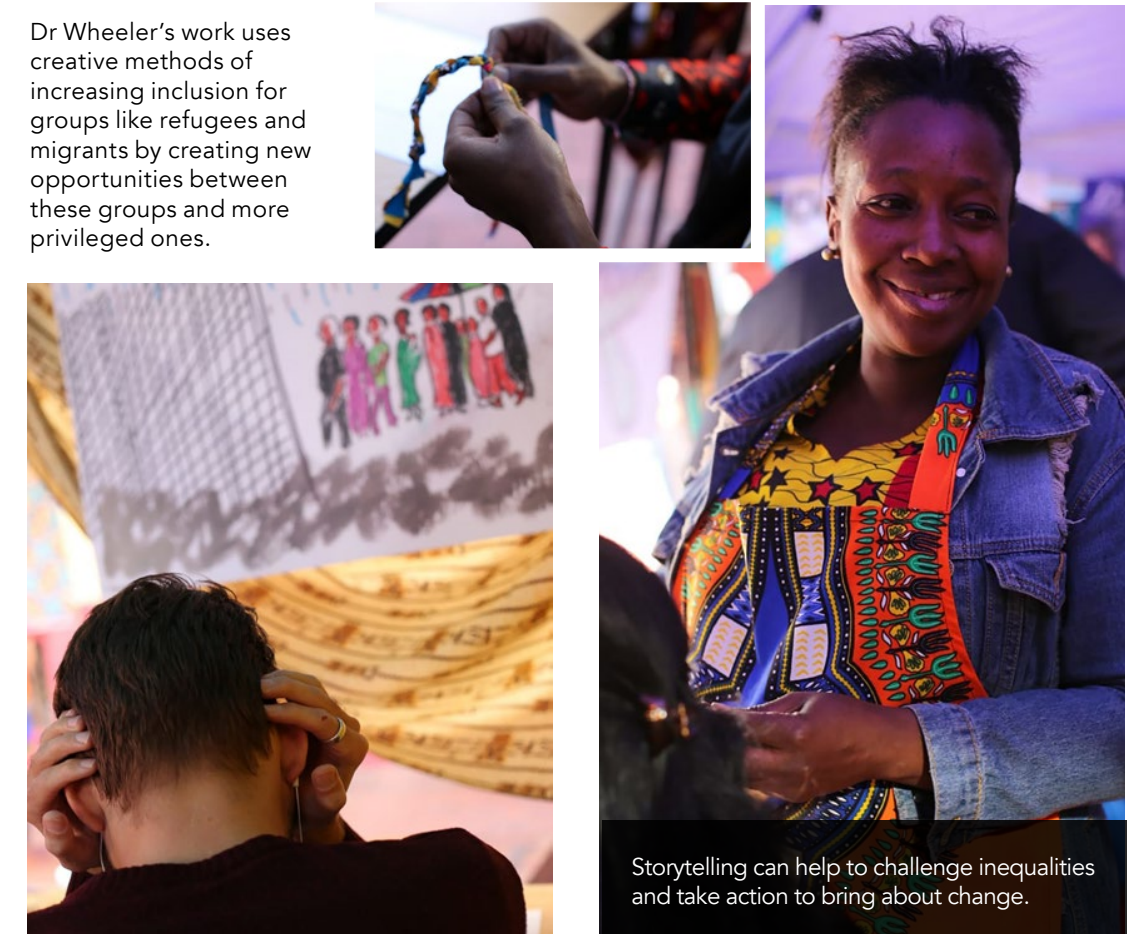

particular identity groups, then $\mathrm{Dr}$ Wheeler's work uses creative methods of increasing inclusion for groups like
refugees and migrants by creating new opportunities between these groups and more privileged ones. Dr Wheeler argues that exclusionary narratives in the media and from politicians scapegoat and marginalise these migrants and other groups by misrepresenting Exclusionary rely on labels, like 'refugee' 'migrant'. Dr Wheeler's research shows that labels offer a simplified understanding of the identity of different groups in society. Instead, Dr Wheeler argues that we need to promote storytelling that the complexity of other people's experiences and uses intersectiona PAR to become more understanding and accepting of differences.

Intersectional PAR is, by its nature, practical and active. Therefore, Dr Wheeler has outlined an example to make it clear to the reader how storytelling based on dialogue and inclusion can create a bridge between
social divides. Dr Wheeler explores nationality in South Africa through a storytelling-based approach. people's paths through life.

nd 'Coloureds' are disadvantaged in Segregrion plysts in housng sont. these groups live separately and in more precarious conditions than the generally wealthier white community. These different forms of exclusion can also einforce one another, so that migrants from other African countries often face severe poverty.

Dr Wheeler's research included using storytelling to attempt to cross this social divide and create understanding between them. To do this, Dr Wheeler worked with two groups. The first was a group of refugees and asylum seekers from other African countries, Cape Ty Cape Town. The second group were igrants from a position of privilege, choice. While each group comes from significantly different backgrounds, issues surrounding race, migration, and they also have shared experiences.

Dr Wheeler asked each group to develop a story about a time they felt at home or not at home in Cape Town. The groups used drawing, sculpting, drama, writing, photography and other creative techniques to create their individual stories. individual stories.
They used digital $\begin{array}{ll}\text { An intersectional approach is a political } & \begin{array}{l}\text { They used digital } \\ \text { technology to } \\ \text { produce their own }\end{array}\end{array}$ and recognising how it impacts on They then came the stories and

migrants for social problems. Despite apartheid ending more than 20 years ago, social divides between different excluded groups, including Blacks


experiences more fully, and challenge their own assumptions about labels (such as 'refugee' or 'Black').

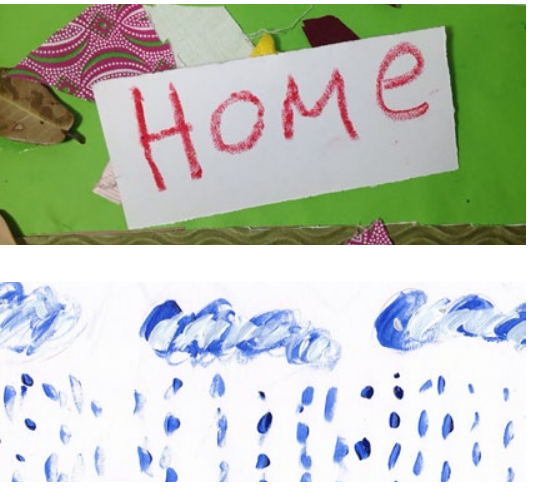




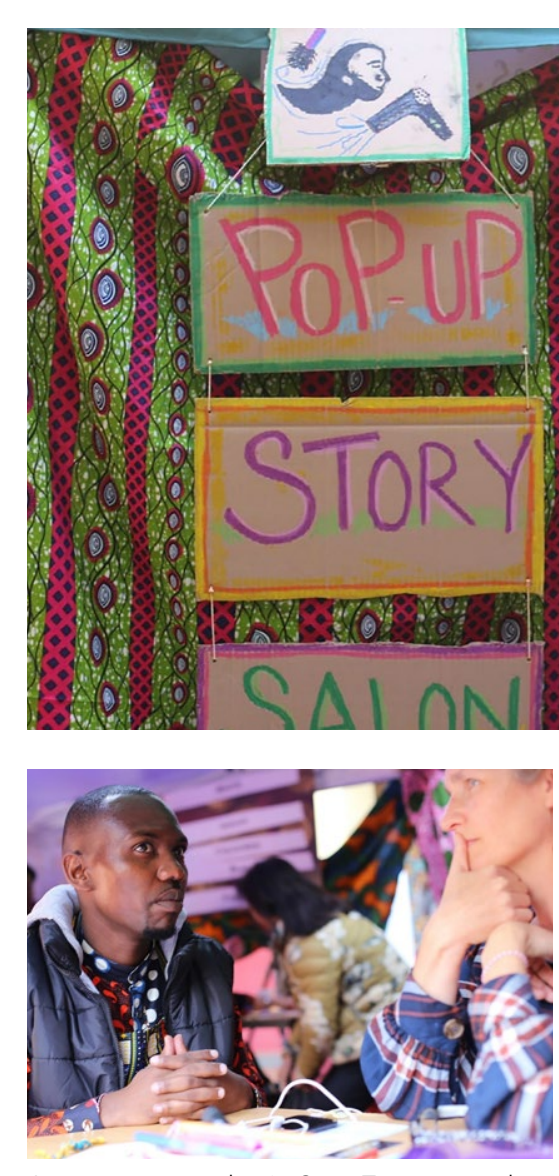

A pop-up story salon in Cape Town created an
opportunity for anyone to listen to different stories of people's experiences of being at home, and to have a mean
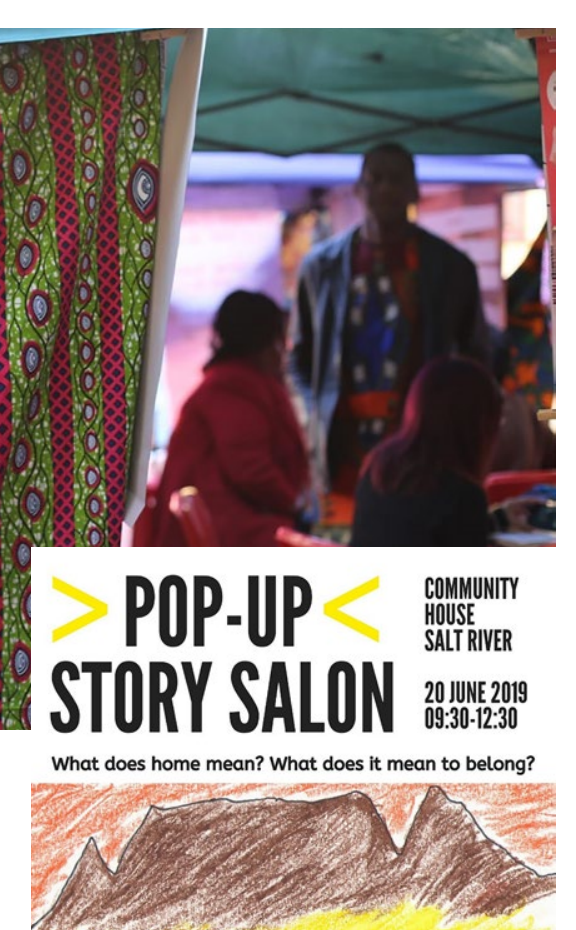

2 WATCH UISTEN,

ST STRRES OF BELNANGIII MIGRAAT COMMUNITY

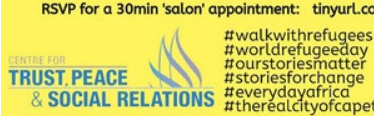

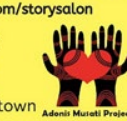

It is actually in exploring differences that we are able to build an understanding of these differences and create more positive dynamics between groups.

In particular, Dr Wheeler notes the label refugee. While this term is South Africa, it evokes feelings of shame, weakness, powerlessness, and a failure to provide. To much of South African society, the term refugee suggests a person who has nothing to offer. The label 'refugee' is therefore contradictory. The groups involved identified how labels, such as 'refuge need to be challenged by going beyond labels to understand every day experiences.

Intersectional PAR, Dr Wheeler notes, is a painful approach. It involves facing up to hard truths. However, it is groups to move beyond supeficial

labels and confront the complexities of individuals. By exploring the concept DrWheeler has taken a practical approach to understanding the impar of exclusionary narratives and helped to dismantle negative stereotypes.

\section{THE STORY SALON}

Following the storytelling process with the two groups, they combined to offer a pop-up story salon in Cape Town. The purpose of the pop-up story salon was to create an opportunity for anyone in Cape Town to listen to different stories of people's experiences of being at home, and to have a meaningful conversation about held in a lact hall, decora $w$ wh storytellers' own artwork, and famous for its role in organising anti-Apartheid room was already confronted with new perspective on what it's like to be a marginalised group in South Africa.

Under gazebos, chairs and tables were setup, offering an inviting environmen like salons in townships. With hair weaving and snacks on offer, visitors quickly arrived to listen to the refugees' story in person, therefore able to connect directly with the storyteller and really come to understand a different person's life.

This salon was created to maximise the impact of stories to create dialogue given s list of rules to ensur we the most out of the event, thes like 'be respectful', 'be aware of your privilege' and 'listen to hear, not just to respond". This was a rare chance to hear the stories of real people and engage with them deeply and authentically.

Despite early apprehension, torytellers became more confident as the event progressed. They enjoyed having the platform for meaningful conversation about their stories, and visitors were invariably moved by the occasion. Afterwards, visitors recorded video messages addressed to the City of Cape Town and what they hoped could change. Prejudices and assumptions were challenged understanding of the treater understanding of the true stories of Africa, and of their common ground.

DrWheeler's research is fundamentally practical, involving a high level of participation from both the researchers and their subjects. It relies on using creative methods and storytelling to unpick the negative narratives surrounding migration, refugees, and other marginalised groups. In doing so, we can build narratives and share stories across social divides. Regardless of your age, gender, nationality, ethnicity, or any other socially constructed aspect of your dictic you have a story worth telling and acceptance of difference.

\section{2 \\ Behind the Research \\ Dr Joanna Wheeler}

E: Joanna.wheeler@coventry.ac.uk T: +4407951852213 @ @joanna_wheeler

\section{Detail}

\section{Bio}

Dr Joanna Wheeler is a Marie Curie Research Fellow at the Centre for Trust, Peace and Social Relations, Coventry University, UK and Senior Research Fellow, University of Western Cape, South Africa. She has conducted more than 50 storyteling processes nd collective forms of storytelling.

\section{Funding}

- Marie-Sklodowska Curie Action

\section{Collaborators}

Adonis Musati Project, South Africa

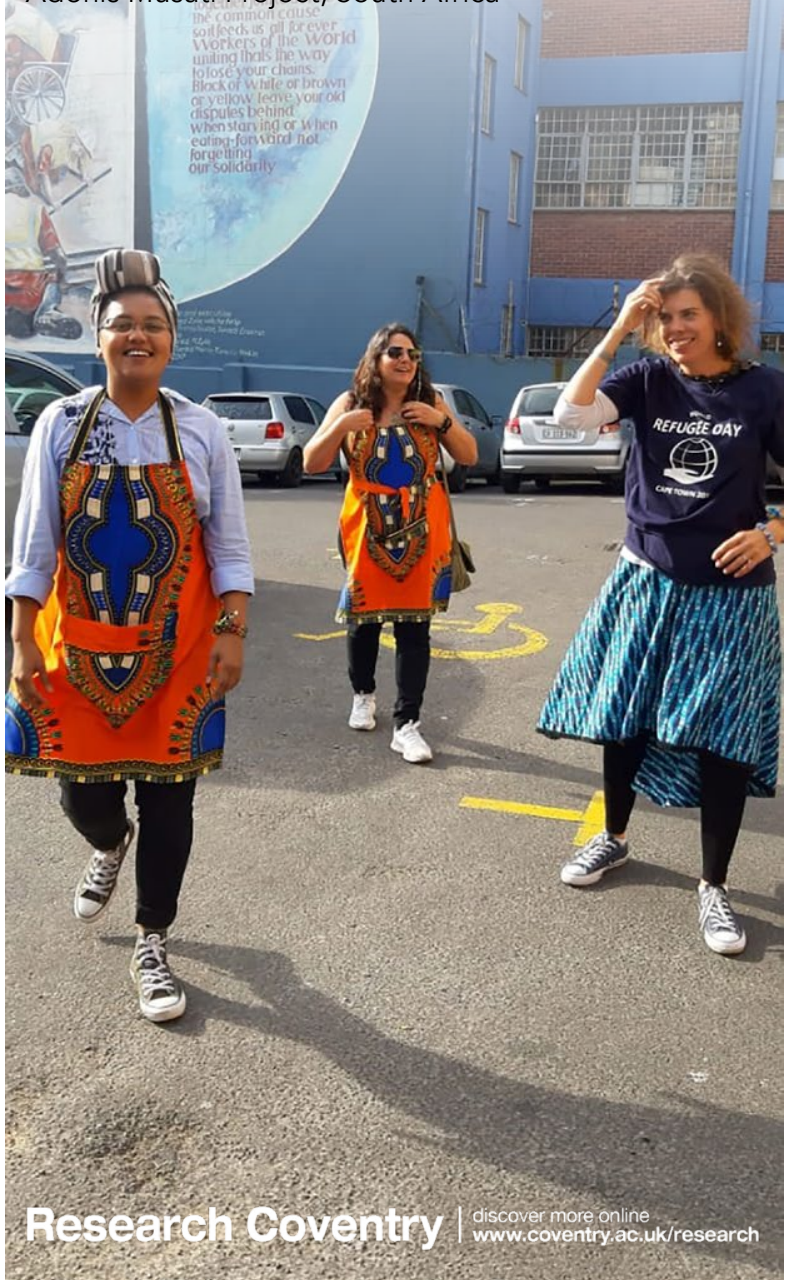

\section{Research Objectives}

Joanna Wheeler's creative storytelling approach combines a participatory collaborative methodology with the creative action on pressing social issues.

\section{References}

Joanna W., Shahrokh T., Derakhshani N. (2018). Transformative Storywork: Creative Pathways for Social Change. Pp 1-22.

Joanna W., Shaw J., Howard J. (2020). Politics and Practices of Inclusion: Intersectional Participatory Action Pextord University Press and Commun

Joanna Wheeler - Coventry University. [Online] Pure Portal. Available at: https://pureportal.coventry.ac.uk/en/persons/ joanna-wheeeler [Accessed 19.07.2020].

Transformative Storytelling for Social Change. [Online] Transformative Story. Available at: https://www. transformativestory.org/[Accessed 19.07.2020]

Inside/Out Pop-Up Story Salon. [Online] Medium. Available at: https://medium.com/@joanna wheeler/inside-out-pop-

\section{Personal Response}

How can ordinary people introduce inclusive storytelling into their everyday lives?

II Inclusive storytelling focuses on how you can tell rea to stop and think about your experiences. Using your creativity with help you express them and make sense of what they mean. Seeking out and listening to genuine stories from others can also be an important way of
understanding different points of view.

Research Centre Trust, Peace and ocial Relations

Coventry sily 